\section{SOBRE OS MODOS DE RESIGNAÇÃO MOMENTÂNEA DA VONTADE, SEGUNDO SCHOPENHAUER}

\author{
Diego Carlos Damasceno \\ Mestrando em Filosofia - UnB
}

\begin{abstract}
Resumo: $O$ presente artigo tem como objetivo elucidar a filosofia de Arthur Schopenhauer em seu aspecto mais desconhecido: os modos como o homem pode lidar com a vontade, diminuindo seu sofrimento. Deste modo, ocorre uma abordagem do seu pessimismo que, ao mesmo tempo, incorre em uma filosofia da vida, pois há uma explanação sobre a origem da vida em seu devir e ciclo natural. Esse pessimismo aliado a uma filosofia da vida torna sua filosofia um tanto existencial, visto que o autor versa sobre os sofrimentos da existência e como diminuí-los neste mundo de desejos violentos. Por fim, este artigo visa abordar como a vida asceta é, também, fundamental a uma anulação da vontade e do sofrimento de ser incompleto.
\end{abstract}

Palavras-chave: Vontade; Representação; Vazio da existência; Ascetismo.

\begin{abstract}
This article aims to elucidate the philosophy of Arthur Schopenhauer in its most unknown aspect: the ways in which man can deal with the will, reducing his suffering. In this way, an approach of his pessimism takes place that, at the same time, incurs a philosophy of life, for there is an explanation about the origin of life in its becoming and natural cycle. This pessimism combined with a philosophy of life makes his philosophy somewhat existential, since the author deals with the sufferings of existence and how to diminish them in this world of violent desires. Finally, this article aims to address how the ascetic life is, also, fundamental to an annulment of the will and suffering of being incomplete.
\end{abstract}

Keywords: Will; Representation; Empty of existence; Asceticism.

\section{O mundo como vontade e representação}

Em O mundo como vontade e representação, Schopenhauer apresenta um idealismo volitivo com forte influência kantiana. Sua filosofia está pautada em uma vontade imanente como coisa-em-si que se manifesta nas coisas e inclusive nos seres vivos. Vontade esta como base fenomênica do Universo. Ela é o "véu de Maia" que não permite a intuição imediata da consciência à essência das coisas. Ela se manifesta como uma escala etiológica provindo de sua essência transcendente até as coisas concretas. É a Vontade como coisa-emsi que se manifesta na realidade como vontade fenomênica. Passando daquilo que se tem muita vontade àquilo que tem pouca. Passando das coisas imóveis da natureza aos seres vivos e ao ser humano.

O mundo é vontade e representação porque é em si vontade e fenômeno. Ele é representação desta vontade, é vontade positivada, é seu fenômeno. Aqui percebemos a forte influência platônica na filosofia schopenhaueriana. Pois, segundo ele, pode-se partir da vontade fenomênica, objetivada nos corpos sensíveis, e alcançar a vontade transcendente como coisaem-si. Logo, o mundo como representação assemelha-se ao mundo das sombras, e a vontade como coisa-em-si assemelha-se ao mundo das ideias. Ou seja, os fenômenos do mundo são abstrações que o ser humano faz em sua sensibilidade. Percebe-se a mera aparência das coisas. Apenas a sua representação que o próprio indivíduo produz. Todavia, a essência criadora do fenômeno positivo, a essência transcendente e imutável, em relação aos fenômenos, é a própria vontade. 


\section{Diego Carlos Damasceno}

Em sua cosmologia, o filósofo apresenta uma manifestação da natureza de forma bastante diferente do Idealismo de Hegel. Em Hegel percebe-se uma manifestação criadora de uma Razão, o Absoluto, como um deus-artífice do mundo e dos homens, e com um objetivo em reconhecer-se. Manifestando-se assim, positivamente, em forma de História. Em Schopenhauer a realidade fenomênica, ou positiva, é substrato, "sombra", ou mera aparência de uma vontade criadora e, acima de tudo, irracional. Não há razão na existência deste mundo e nem razão para a existência humana. Ela é a própria manifestação da vida em sua forma mais irascível e visceral. Nela não há objetivo definido, como a Razão hegeliana. São duas filosofias opostas.

\section{O sofrimento humano gerado pela vontade}

O ser humano é o ser vivo com mais vontade intrafenomênica entre todos os outros e é dotado de consciência, também é o que sofre mais. Pois esta vontade é lei cósmica do universo, devir que se transforma perpetuamente, gerando vida e morte. No ser humano ocorre mais acentuadamente o carma da: necessidade, desejo e vontade.

O homem sofre primeiramente porque, como ser vivo e desejante, necessita de algo, em seguida sofre por não poder ter suas necessidades satisfeitas, ou porque, já tendo sua necessidade satisfeita, surge um vazio insustentável em seu ser, fazendo-o retornar ao jogo infinito de querer e satisfazer, desejar e saciar, prazer e dor. $\mathrm{O}$ homem sofre quando não afirma plenamente sua vontade e também sofre porque jamais conseguirá afirmá-la completamente. Pois, como ser de consciência superior, o ser humano está sujeito a sofrimentos e dores superiores as dos outros seres vivos, tais como sofrimentos além dos que o corpo e o instinto lhe impelem, por exemplo: a fome, a sede, a dor física, a morte.

O homem está sujeito a dores de caráter superior. "Dores metafísicas" ligadas ao ego ou a psiqué, depressão, solidão etc. Há uma tentativa imanente ao homem em afirmar seu ser e superar-se superando até a morte, se possível. O vazio da existência é a base disso. É um vazio que busca ser preenchido pelo todo do mundo, por todas as vontades existentes, pelo em-si das coisas. O qual jamais será preenchido e sempre acompanhará o devir do homem em seu movimento.

Schopenhauer nos fala sobre o homem ser apenas um fenômeno gerado pela vontade em um constante processo de vir-a-ser, de ser pleno, de afirmar-se e satisfazer todos os desejos que o mundo lhe impõe. Porém, isto não é possível. $\mathrm{O}$ homem está fadado ao eterno movimento de desejar, satisfazer-se (se possível), e sentir novamente um tédio, um vazio interior, de um querer que nunca se satisfaz, tornando-se incompleto e infeliz por toda vida. Esse vazio o impele a querer novamente, a querer sempre, e assim sofre perpetuamente. Pois, deste modo, sua consciência não escapa desse devir fenomênico do mundo como representação e desejo. $\mathrm{Ou}$ seja, sua consciência imerge cada vez mais na aparência das coisas, tornando-se mais "mundana" e suscetível a novos quereres. Deste modo a influência do estoicismo fica evidente na obra de Schopenhauer, porque ele apresenta uma filosofia existencial e uma moral ascética - a qual será abordada no último item - semelhante ao pensamento estoico, o 


\section{Diego Carlos Damasceno}

qual infere que a negação dos desejos mais "mundanos" podem elevar a alma, ou pneuma, dos sofrimentos do mundo e aproximar o indivíduo da ordem cósmica.

Os próximos subitens versarão sobre a anulação momentânea da vontade e dos seus efeitos. Ou seja, a esperança infeliz de superação completa da vontade. Bem como a arte relaciona-se com a transcendência necessária à uma saída deste mundo de desejos constantes, ou como a experiência estética coloca o espectador, e também o artista, em uma realidade intrafemomênica de êxtase e esquecimento das dores em uma intuição com a obra de arte. Bem como o suicídio não se mostra uma saída feliz para as dores do mundo. Ocorrerá também uma explanação da vida asceta e anulação da vontade presente no indivíduo.

\section{O sublime como uma intuição pura do mundo como representação}

O homem pode por pouco tempo livrar-se da angústia de viver ao elevar-se espiritualmente do mundo dos objetos. Para isso, faz-se necessário a presença imediata de objetos que devem ser contemplados de forma completamente liberta do querer e das vicissitudes humanas. Deve haver uma contemplação tão pura e desprovida de vontade que o homem possa se encontrar em um estado de sublime estético, onde ele se esquece de sua personalidade, de sua consciência, de seu eu, tornando-se sujeito puro com a ideia em um estado de transcendência de seu corpo (incluindo do princípio da razão), e consequentemente, de sua vontade objetivada. O sentimento do sublime é um êxtase surgido quando há intuição pura para além da representação. $\mathrm{Ou}$ seja, é na estética de uma paisagem, por exemplo, que o homem pode transcender espiritualmente a sua existência positiva, a sua vontade e a representação das coisas, e unir-se à ideia, à coisa-em-si ou à obra contemplada, como um sujeito puro do conhecimento. Esta sensação de bem-estar, felicidade e prazer a que se denomina sublime, é o esquecimento de si como ser de angústias de necessidades, de quereres e de vontades por parte do indivíduo. Em um estado sublime, a vontade é anulada, assim infere o autor:

[...] Podemos por meio dos objetos presentes, como por meio dos objetos afastados, subtrairmo-nos a todos os males; basta para isso sermos capazes de nos elevarmos a uma contemplação pura desses objetos; chegamos assim a acreditar que só estes objetos estão presentes e que nós mesmos não o estamos de modo nenhum: neste estado estamos libertos de nosso triste eu; tornamo-nos a título de puros sujeitos que conhecem, completamente idênticos aos objetos; tanto a nossa miséria lhes é estranha como semelhantes momentos, se torna estranha para nós mesmo. Só o mundo considerado como representação permanece; o mundo como vontade desapareceu (SCHOPENHAUER, 2001, p. 209).

O sublime como elevação estética surge após um combate entre formas contrárias que visam superar violenta e conscientemente a vontade, pondo, assim, o eu acima da vontade e de suas formas objetivas. Após a superação da vontade como representação, faz-se necessária a manutenção deste estado, mesmo que dure pouco tempo, e procurar esquecer qualquer forma corpórea à sua consciência. Entretanto, como o corpo é vontade, a vontade redobra sua presença e se mostra viva e novamente perceptível ao homem. O sublime é o êxtase supremo sobre a fatídica existência humana, tudo o que é sublime é extático e eleva o 


\section{Diego Carlos Damasceno}

sujeito além de si e além de suas idiossincrasias, tal como afirma o autor:

[...] se, na qualidade de puro sujeito que conhece, contempla de uma maneira serena os objetos temíveis para a vontade; se ele se limita a conceber as ideias estranhas a toda relação; se, por conseguinte, para com prazer nessa contemplação; se, enfim, ele se eleva, por esse fato, acima de si mesmo, acima de sua personalidade, acima da sua vontade, acima de toda vontade - neste caso é o sentimento do sublime que o preenche; ele está num estado de êxtase, e é por isso que se chama sublime ao objeto que ocasiona este estado. [...] (SCHOPENHAUER, 2001, p. 212).

A arte é, para Schopenhauer, uma atividade altamente libertadora. Ela é a fruição. Ela é o resultado imediato da intuição do homem com o mundo. Desta intuição o homem representa seu ser volitivo e o mundo como fenômeno em forma de arte. A arte é a representação da vida humana, com suas dores e alegrias. Os diversos tipos de arte demonstram o estado de espírito em que se encontram os seres humanos. Tal como há uma escala etiológica em relação aos fenômenos, há uma escala que demonstra os fenômenos da vontade nas obras de arte. O ápice desta escala é a música, sublime por excelência. Visto que é totalmente metafísica, a música alcança o íntimo como coisa-em-si e vontade pura. Ela exprime os sentimentos em suas formas mais puras.

A diferença entre o sentimento do belo e o do sublime é que o sentimento do belo é imediatamente sensível, aquilo que é belo o é imediatamente contemplado e reconhecido naturalmente. Enquanto que o sublime requer um esforço de espírito para ser alcançado, requer a renúncia à vontade como representação e suas formas objetivas. Porém, a manutenção do sublime infelizmente é temporária.

\section{O suicídio como tentativa infeliz de preenchimento do vazio da existência}

Schopenhauer é comumente conhecido por ser um filósofo pessimista acerca da existência humana. É corriqueiro que leigos em sua filosofia associem seu pessimismo à certeza do suicídio, entendendo assim que o suicídio é aceito por um filósofo que entende a existência humana como um sofrer perpétuo, suicidar-se seria o modo de saída do mundo e das paixões que o mundo e a vontade impõem aos indivíduos. Não obstante, a seu pessimismo, o autor rejeita o ato do suicídio como meio de alguém livrar-se da infelicidade intramundana.

É necessário um esforço por negar a vontade e, com isso, cessar o ciclo de sofrimento que o devir volitivo impõe. Entretanto, não se deve confundir a negação parcial da vontade, obtida mediante o ascetismo (o qual será o próximo item a ser discorrido), com uma negação falsa que não atinge a vontade: o suicídio.

O suicídio é a negação consciente, infeliz e ilusória deste mundo. Ele é a afirmação absoluta do querer que tudo quer e não se satisfaz senão deixando de viver. $O$ suicida entende que cessar o viver cessa o querer.

O suicida não quer a morte, ele não deseja a extinção de sua consciência e não desdenha da vida. A própria consciência precisa ser consciência de alguma coisa, como diz Husserl. Ela necessita de um tempo presente, a consciência em sua intencionalidade não pode, de per si, desejar não existir. A morte é entendida como outro caminho para a vida, ou melhor, a morte como autossupressão é entendida como meio de tentativa de afirmação da vida e afirmação da vontade. Ela é entendida como a outra chance à felicidade. 


\section{Diego Carlos Damasceno}

O suicida está insatisfeito com sua vida, aquela que não the permite realizar seus desejos, consumar sua vontade, aquela que não lhe traz a plenitude de si, de seu vazio existencial, aquela que não lhe permite afirmar seu ser no mundo sem obstáculos.

Todo suicida crê em uma vida póstuma, e nem ele nem sua consciência podem, no mais íntimo de seu ser, de seu pensamento, imaginar um nada após a morte. A morte é entendida como a passagem a outro ser. Cada suicida é, enquanto indivíduo, uma objetivação do querer-viver. Este querer-viver quer se afirmar no mundo, por isso tenta se objetivar. Quando já não há mais sucesso nessa batalha em querer se afirmar neste mundo, o querer-viver se volta contra o fenômeno da vontade (corpo, indivíduo) e, como já entende não poder mais se afirmar de outra maneira no mundo, esta vontade suprime seu fenômeno.

A vontade é senhora do universo. A lei cósmica, regida pela vontade, busca o equilíbrio absoluto entre aquilo que se mostra e aquilo que se nega, entre aquilo que se afirma e aquilo que é suprimido. A vontade se faz múltipla ao se objetivar no mundo, ao se fenomenizar nele. Cada objetivação se afirma negando as objetivações precedentes. Cada afirmação de si confronta-se com a realidade já objetivada, pois cada fenômeno representa o ponto de equilíbrio da justiça cósmica gerada pela força motriz. A vontade transcendente, como força motriz, confronta-se a si mesma a cada fenômeno. É nela que surge um combate de si consigo para gerar o movimento, ela se dilacera para se recriar, ela é autotrófica ao nutrir-se de si mesma. Já o suicídio demonstra esta contradição entre a vontade como fenômeno (positivo) e a vontade transcendente como coisa-em-si. Pois ocorre um embate intrafenomenal, onde o fenômeno é levado a negar-se visando a coisa-em-si. O suicida visa a plena vontade, a vontade mesma e sua anulação, a plena realização de si como indivíduo.

Como anteriormente dito, após a morte ainda há vontade. É ilusório ao suicida o desejo de livrar-se do desejo. A vida é um carma. O sujeito provém da vontade e retorna a ela, o suicídio é um retorno forçado, ilusório e doloroso. Ao tratarmos de suicídio estamos tratando de uma autodestruição consciente realizada por um indivíduo. Aquilo que é eliminado no individuo é meramente seu corpo. A coisa-em-si, existente em cada ser, encontra-se em uma dimensão extrafenomenal. A destruição do fenômeno da vontade não atinge e não cessa a vontade. A morte não é o fim do sofrimento e a vontade não pode ser negada através da eliminação de seus fenômenos, pois como ela não é física, ela não pode ser destruída fisicamente. Escreve Béziau:

[...] Ao se objetivar a Vontade se faz múltipla, e cada objetivação particular se afirma negando as demais; tal afirmação é levada ao máximo até o ponto de equilíbrio para além do qual o mundo já não seria possível. Havemo-nos com o pior dos mundos possíveis, o mundo dos fenômenos é uma luta incessante dos fenômenos entre si. [...] O suicídio é, antes, uma contradição entre a vontade como fenômeno e a vontade como coisa-em-si, o que leva a crer numa luta intrafenomenal aparecendo como a negação de um fenômeno por si mesmo. [...] Engana-se quem acreditar que, ao se dar a morte, porá fim a seus sofrimentos. A morte não é a aniquilação, e, de um ponto de vista fenomenal, a vontade de viver não diminui com o ato do suicídio. O que diminui é, talvez, a sua força de objetivação. [...] (BÉZIAU, 2012, p. $129-130$ ).

O suicida almeja negar a vontade. Ora, este é um desejo em comum entre os homens, todavia, no suicida este desejo torna-se uma 


\section{Diego Carlos Damasceno}

estupidez e uma inutilidade. O filósofo alemão articula sua obra entre vontade como coisa-emsi e o mundo fenomenal como sua objetivação. Este mundo é repleto de constante sofrimento, ele é a forma visível de um querer que muda a cada instante, que não se satisfaz em nada no mundo, pois "o mundo é o inferno, e os homens dividem-se em almas atormentadas e em diabos atormentadores" (SCHOPENHAUER, 1955, p. 8). Outrossim, o filósofo nos fala sobre uma possibilidade para a supressão da vontade, na qual o suicídio incorre justamente o caminho inverso para esta supressão. Pois, como anteriormente dito, a negação do corpo não nega a vontade, a morte não é o fim do sofrimento. Cada vida é uma possibilidade de afirmação ou de negação da vontade, cada ser pode encontrar um caminho para reduzir seu sofrimento ou para inibir sua vontade. O suicida dá fim a esta possibilidade. Novamente escreve Béziau sobre Schopenhauer:

[...] O querer-viver não pode ser destruído fisicamente, pois ele próprio não é físico. $\mathrm{Na}$ maior parte do tempo, o suicídio reside nessa confusão entre fenômeno e coisa-em-si; ao se destruir o fenômeno, acredita-se destruir de um mesmo golpe a coisa-em-si, o que equivale a acreditar que para matar o bandido, baste atirar em sua sombra. [...] (BÉZIAU, 2012, p. 131).

O filósofo também discorre sobre a questão do suicídio ser ou não um ato injusto. Mediante as críticas ao suicídio expostas acima, era de se imaginar que o autor entendesse que o suicídio fosse algo que gerasse injustiça. Entretanto, ele entende que, como o suicídio diz respeito a um indivíduo, este ato de dar fim a vida não incorre em prejudicar a vida de outras pessoas. $\mathrm{O}$ suicídio não é injusto porque não cerceia a afirmação da vontade de outras pessoas, ele não nega a possibilidade de concretude volitiva ou não nega a possibilidade de existência de ninguém além dele.

Como diz o poeta Guilherme de Almeida, "esta existência não vale a angústia de viver"1. De fato, o peso desta vida pode ser insustentável para qualquer pessoa, principalmente para aquelas que têm um desejo incessante em afirmar seu ser no mundo. Estas sofrem por não satisfazerem seus desejos, ou por não se afirmarem no seu querer sem dificuldades, sem obstáculos. Por isto não se deve julgar um suicida, ninguém é capaz de medir a angústia alheia, ninguém por nenhuma moral, seja a lei do Estado ou a moral religiosa, podem avaliar ou sequer punir a conduta de um suicida. Neste ponto Schopenhauer difere bastante da moral kantiana. Isto porque nos Fundamentos $d a$ Metafísica dos Costumes Kant infere que os seres racionais têm uma responsabilidade moral em preservar sua vida e que isto não poderia, naturalmente, se tornar um imperativo como lei universal da natureza, já que, segundo ele, uma natureza cuja lei fosse destruir a própria vida, pela mesma sensação cuja determinação é animar o fomento da vida, seria contraditória e não poderia subsistir como natureza ${ }^{2}$.

A sensação de suicídio por si já é um castigo ao suicida. Ela é uma vontade mal consciente de suas possibilidades e que quer afirmar-se negando-se a si como fenômeno. O quererviver não pode ser suprimido pelo suicídio. Ele somente é anulado quando há o conhecimento volitivo sobre si, ou uma espécie de refletividade

\footnotetext{
${ }^{1}$ ALMEIDA, Guilherme. Esta vida. Disponível em: http://www.jornaldepoesia.jor.br/gu.html\#estavida Acesso em: 12 jan. $201617: 38$

${ }^{2}$ KANT, Immanuel. Fundamentos da Metafísica dos Costumes. Rio de Janeiro: Editora Tecnoprint p.71
} 


\section{Diego Carlos Damasceno}

da vontade, onde ela se volta contra si anulando-se.

\section{A supressão da vontade através do ascetismo}

Anterior a uma exposição sobre a supressão da vontade e sobre o ascetismo, faz-se necessária uma explicação acerca da maldade e da bondade. Assim como a vontade transcendente representa uma justiça eterna e universal, as atitudes e paixões humanas também se encontram no seio de um equilíbrio universal, onde cada ação terá uma reação.

O homem malvado é aquele que comete injustiça. Ele é o ser que não se contenta em simplesmente afirmar sua vontade de viver em um corpo, ele tenta negar esta vontade existente no outro. Ou seja, o outro torna-se um empecilho para uma afirmação de si para além de seu corpo. Com isso o sujeito malvado suprime a vontade no outro indivíduo. Isto demonstra um egoísmo presente neste homem, o qual o impele a uma vontade tão violenta que ultrapassa a afirmação de seu próprio ser e torna-se capaz de negar o direito volitivo (vontade de viver) do próximo.

Vemos algo análogo a isso em Genealogia da Moral, quando Nietzsche nos fala sobre o ressentimento existente naqueles que não podem afirmar sua vontade de potência e não acompanham o modo de ser da realidade. São extáticos, "conservadores" e infelizes. Por isso, introjetam ressentimento e culpa nos outros. Os sacerdotes, artífices de uma moral rígida e aparentemente deontológica, intentam nivelar a sociedade em sua forma mais medíocre e racional. Como uma moral racionalista. E assim violentam o outro em seu direito de vontade de ser, de afirmar-se, e, nos dizeres de Nietzsche, impedem o aparecimento do alémhomem ou homem-da-passagem, que superaria toda essa moral do ressentimento em prol de uma afirmação autônoma de sua vontade, de seu ser e tornar-se transvalorador de todos os valores.

Entretanto, diz Schopenhauer, a maldade e o sofrimento impelido aos outros indivíduos graças à natureza da própria vontade que é uma fonte inesgotável de sofrimentos - volta-se ao seu agente. Sendo assim, a crueldade, que é o grau superior da malvadez, representaria um alto nível de sofrimento. Pois, em cada ser há um sofrimento interior, este sofrimento não é diminuído com a prática malévola em ter alegria com a dor do outro. A dor do outro também é sua dor. Todos os seres encontram-se no mesmo plano existencial da vontade, todos são iguais, todos sofrem igualmente. Porém, o homem malévolo não tem consciência de que sua consciência e sua existência também são parte do outro.

Portanto, destruir o outro ou fazê-lo sofre o mal é incorrer em um pecado a si mesmo, é martirizar a si próprio. Visto que todos são fenômenos da mesma vontade, todos são parte do mesmo ser. A vontade pune o injusto com o mais elevado sofrimento, e pode, também, agraciar, de forma indireta, o justo que sabe conviver consigo e diminuir seu sofrimento. Procurar aliviar-se infligindo mal ao outro é enganar-se grandemente e torna-se vítima de si mesmo, porque nunca se resignará e estará constantemente perturbado pelas dores do mundo e constantemente vazio. O mais infeliz dos seres.

Aquilo que é bom, perante a vontade, é algo relativo. Ela nunca se satisfaz e nunca se 


\section{Diego Carlos Damasceno}

mantém constante. Logo, aquilo que é bom o é mediante um certo desejo consumado momentaneamente, e daí pode-se concluir que não há um bem em si (de forma positiva) ou um conceito de bem moralmente aceito. Este bem em si surgiria através da supressão total da vontade (o que será abordado mais a frente). $\mathrm{O}$ autor nos diz que "para ela não existe bem supremo, bem absoluto, apenas bens instantâneos" (SCHOPENHAUER, 2001, p. 380).

A noção de justiça que se opõe à malvadez vem a afirmar que o sujeito deve fazer o que é certo mesmo na ausência de uma moral instituída ou na falta de leis em um Estado. Este ato correto é justamente a não negação da vontade do outro, é aumentar seu bem-estar sem fazer o outro sofrer, é respeitar o outro como parte de si (além de seu simples fenômeno).

A bondade confunde-se com o ascetismo, ela é uma ação desinteressada para com o outro, ela é realmente nobre. A bondade é justamente o ato de propiciar a afirmação da vontade de viver no outro, é afirmar sua vontade (pois a bondade não é autossupressão de sua vontade), visando um equilíbrio com os demais fenômenos. O homem bondoso visa uma equidade com seu semelhante, ele não se percebe tão diferente do outro. Afinal, todos sofrem. Juntos os homens poderiam perceber que suas consciências não são indiferentes ao mundo, que suas existências podem atingir um nível um pouco mais sublime.

Pois, se a vida é sofrimento, a bondade entre os homens é com-paixão (pathos comum a dois indivíduos, uma espécie de abdicação de sua individualidade) é compadecer-se de seu semelhante em tentar afirmar-lhe a vida diminuindo seus sofrimentos. Se praticar o mal nos traria ainda mais dor, praticar o bem pode dissimular esta vontade. Essa compaixão é união com o todo, é superar a barreira fenomênica e obter uma espécie de redenção do sofrimento de viver. Tal como diz o filósofo:

[...] Ela nasce do fato de que uma ação deste gênero, que tem como origem o reconhecimento do nosso próprio ser sob a aparência de outro, é ao mesmo tempo a uma confirmação desta vontade, de que o nosso verdadeiro eu não reside só na nossa pessoa, no fenômeno que somos, mas também em tudo que vive. [...] Sem dúvida que o conhecimento que ele tem da sorte do homem em geral impede que sua serenidade vá até o contentamento; mas, todavia, como ele reconhece constantemente o seu ser em tudo que vive, resulta disso uma espécie de igualdade e mesmo uma serenidade de alma, visto que um interesse que se estende a uma quantidade inumerável de fenômenos não pode transformar-se em ansiedade, como aquele que se encontra em um só. [...] (SCHOPENHAUER, 2001, p.392 - 393).

O conhecimento do sofrimento do outro também pode orientar o outro indivíduo em direção à abdicação da vontade. Isto se dá por meio da caridade (caritas) inerente ao homem bondoso. Esta caridade em si é piedade, ela surge quando há ciência do sofrimento alheio, na qual o indivíduo o reconhece a partir de suas próprias dores, igualando a dor alheia às suas. A caridade pura e sincera é piedade, àquela que assim não é torna-se amor-próprio. A piedade é a participação e o reconhecimento do sofrimento do outro, ela é uma representação de um sofrimento além de seu próprio fenômeno.

Não há como não abordar outra dimensão bastante singela da sensibilidade humana: o choro. Tal como o ato de rir o ato de chorar é genuíno da espécie humana. O choro é uma reprodução de uma dor, é uma representação 


\section{Diego Carlos Damasceno}

que atinge a essência da dor e que se encontra muito além de uma dor física. $\mathrm{O}$ indivíduo produz uma representação pura de sua dor, ele torna-se digno de compaixão, e, sendo assim; "Chorar é, portanto, ter piedade de si mesmo" (SCHOPENHAUER, 2001, p. 395). Esta piedade de si, presente no choro, é uma tentativa de alívio para seu sofrimento individual, ela é um suplício.

Schopenhauer entende que a supressão da vontade ocorre através da negação do quererviver e que isto conduz o indivíduo às vias do ascetismo. $\mathrm{O}$ indivíduo deve superar essa ilusão de que sua consciência está separada do mundo, ou que sua existência é indiferente ao outro. Com isso, ele entende que o egoísmo natural presente no homem somente tem fim quando o indivíduo toma conhecimento do todo e se entende como parte deste todo. Esse conhecimento da essência do mundo é um calmante para a vontade. Os desejos ligam o indivíduo ao mundo como fenômeno, eles afirmam a vontade; como os desejos visam prazeres, os prazeres reafirmam esta vontade, eles a animam cada vez mais. Ou seja, não buscar intuir a essência das representações sublimando-se do mundo fenomênico e obtendo prazeres mundanos, afirmando ainda mais a vida e o querer-viver, aumenta a vontade e, subsequentemente, os seus males. Percebe-se, assim, a influência direta do estoicismo no pensamento schopenhaueriano.

A abnegação voluntária da vontade, a diminuição constante do querer e, por fim, a aceitação passiva do sofrer vão cessando o jogo volitivo de prazer e dor e elevando o ascetismo. A dor proferida ao outro e que gera prazer, também será sofrida por seu agente, este estado ativo de afirmar seu querer, e ainda mais, afirmando acima do querer alheio, oprime ainda mais um indivíduo. Este indivíduo aumenta ainda mais seu náufrago existencial nesta existência volitiva, ou seja, ao afirmar seu querer menos possibilidades, ele tem de suprimir sua vontade.

Este é o círculo vicioso a que o homem está impelido. Querer ser e afirmar-se gera mais querer. "Toda dor vem do desejo de não sentirmos dor"3, segundo Renato Russo. A via do ascetismo e da purificação espiritual é o que Schopenhauer sugere como o modo verdadeiro de suprimir a vontade, de sublimar-se dela. O ascetismo é a renúncia aos prazeres da vida, é a renúncia em afirmar ainda mais a vida e sofrer o retorno desta afirmação, o que colocaria qualquer homem imerso em um ciclo vicioso neste mundo.

O ascetismo é uma negação do querer-viver como coisa-em-si e não com simples fenômeno, tal como no suicídio. A vida asceta é justamente a mortificação da vontade, uma constante abnegação das alegrias terrenas em prol de uma elevação espiritual em forma de alegria celeste, visto que as alegrias terrenas são sempre pressupostas por novos sofrimentos. Já a renúncia ao desejo explícito e ao desejo de desejar gera uma resignação nobre ao homem asceta. Esta resignação o livra das preocupações e angústias deste mundo, ela cessa o seu sentimento de desamparo (Aufgabe); ela o livra do peso de sua existência.

Esta resignação coincide com a dor (a paixão, pathos, do ser em relação ao mundo). Schopenhauer entende que o indivíduo deve

\footnotetext{
${ }^{3}$ LEGIÃo URBANA. As quatro estações: Quando o Sol Bater na Janela do Teu Quarto. EMI Music, 1989, f. 4
} 


\section{Diego Carlos Damasceno}

aceitar a dor como modo de cessar a Vontade de vida, como modo de purificação ou até mesmo santificação em relação às misérias do mundo. Esta resignação através da dor e renúncia ao prazer encaminha o homem para uma morte sem desespero, sem a aflição natural perante a morte. Este estado de resignação ou estado de sujeito puro do conhecimento é a própria liberdade da vontade, e, para que alguém possa manter-se neste estado, faz-se necessário a constante privação dos prazeres e a alusão às dores a fim de mortificar a vontade. Esta é a vida do asceta. Uma constante abnegação dos prazeres, negação da vontade, negação do egoísmo e das malvadezas. O conhecimento puro da dor é, para a maioria daqueles que almejam libertarse do querer, a única forma de se manter em um estado e em reconhecer o sofrimento do outro, uma constante busca por comunhão com o todo. A dor do mundo cessa o querer e cessa o prazer. Esta resignação representa a forma consciente de subtrair-se da vontade, e elevar o indivíduo a uma serenidade tal que nenhum dos males do mundo e nem mesmo a morte podem oprimi-lo.

Esta posição schopenhaueriana acerca da dor, é bastante polêmica e até mesmo é tida como irreverente, pois ele infere que a dor tem um efeito tão positivo que deve ser contemplada como aquilo que nos faz ter consciência do corpo, isto porque o prazer e o bem-estar cerceiam a capacidade de percepção da consciência humana. Se o homem é impelido por uma vontade irracional, a sua vida cotidiana é algo inconsciente, suas ações tornam-se inconscientes. A dor o chama a atenção e limita sua vontade.

Jesus Cristo é abordado por Schopenhauer como um ícone da personificação da negação do querer-viver. Entretanto, diferentemente dos outros homens, Cristo não era um indivíduo. Ele não era um fenômeno da vontade com suas vicissitudes e quereres. Cristo não era um indivíduo, segundo Schopenhauer. Logo, a filosofia da redenção da vontade proposta pelo autor não se aplica a Ele, pois o Mesmo já se manifesta no mundo de forma perfeita, sem pecado, sem medos, sem desejos; um Sublime personificado em forma de homem. Ou seja, esta filosofia schopenhaueriana diz que o homem comum, que já surgiu como ser neste mundo volitivo, como fenômeno volitivo, este homem é quem poderia suprimir sua vontade imanente ou seus desejos, e diminuir sua infelicidade tendo como paradigma o homem asceta, ou, por exemplo: a figura de Cristo, o qual não poderia suprimir os desejos ou a vontade imanente porque Ele não é fruto da vontade. Ele não proveio da Força Motriz, Ele não tem vontade porque não tem necessidades intramundanas, Ele é perfeito.

Após a supressão total da vontade, o que resta é o nada. O nada é aquilo que compõe o negativo em relação ao ser (o positivo). Tanto o homem quanto o mundo são formas deste ser que é vontade. É o positivo que se opõe ao nada. O nada não é um nada absoluto, ele é um nada em relação a um positivo. A negação do querer-viver é inserção no nada, é a negação da vontade, do ser e do mundo como representação. Esta negação completa da vontade representa um êxtase, uma fruição, um estado de sublime, um estado onde não há princípio da razão (espaço e tempo), e onde há um esquecimento do ser por parte do indivíduo que se encontra em um estado de santidade ou um estado de divindade. Neste estado não há vontade, ela se aniquilou. Então não há mais o ciclo de prazer e dor, ou sede e saciedade em um progresso sem fim. E o homem pode encontrar-se em pleno estado de contemplação sem vontade e com uma leveza de espírito, serenidade ou 


\section{Diego Carlos Damasceno}

purificação de alma jamais sentida enquanto ainda era um fenômeno ativo da vontade e não um sujeito puro do conhecimento.

\section{CONCLUSÃO}

Pode-se concluir que a filosofia de Schopenhauer tem um caráter dúbio. De um lado o autor discorre acerca de uma cosmologia oriunda de uma força irracional como coisa-em-si de tudo (a vontade), por outro lado, ele nos apresenta uma filosofia existencial que mostra o ser humano como indivíduo sofredor e agente passivo em um mundo repleto de desejos e desilusões. Seu lado estoico denuncia a influência do mundo das paixões e aparências como origem do sofrimento deste mundo. A felicidade jamais poderia ser alcançada com a mera satisfação de desejos que se mostram infinitos e crescentes. O vazio da existência é a face mais profunda desse sofrimento, pois é o tédio em não poder ser plenamente aquilo que se quer. É o vazio da satisfação do que é "mundano" e perecível. O consumismo contemporâneo é exemplo deste vazio, porque quanto mais se consome, acreditando suprir um vazio, mais se torna desejoso de consumir, e assim imerge cada vez mais neste carma de desejo.

O filósofo apresenta os dois modos de sublimação momentânea da vontade e o suicídio. A contemplação da obra de arte e a contemplação da própria natureza são modos eficazes de se resignar momentaneamente da vontade e do peso da existência. A angústia é esquecida enquanto o ser se torna sujeito puro do conhecimento e uno com a ideia contemplada. $\mathrm{O}$ indivíduo se torna sublime em um estado em êxtase já se esquecendo de si e de todo querer. Já o suicídio corresponde a uma forma equivocada de eliminar a vontade e o vazio da existência.

Schopenhauer não apoia o suicídio, porém não julga o suicida. Ele demostra como o suicida quer viver, mesmo anulando sua existência física, e que sua consciência busca uma satisfação de suas vontades em uma existência, em outra realidade. No ascetismo é onde se encontra um meio mais profícuo para se anular a vontade. Isto porque como uma filosofia de vida o ascetismo pode, pouco a pouco, anular o querer viver presente em cada ser, e, ao diminuir os desejos, sejam eles necessidades básicas ou de ordens superiores, frear a roda do desejo a ponto de pará-la completamente. Este é o desejo do homem asceta: não mais desejar em um mundo de prazeres e aparências.

\section{Referências Bibliográficas}

ALMEIDA, Guilherme. Esta vida. Disponível em: http://www.jornaldepoesia.jor.br/ gu.html\#estavida Acesso em: 12 jan. 2016 $17: 38$

BARBOZA, Jair. Schopenhauer: a decifração do enigma do mundo. São Paulo: Moderna, 1997.

BÉZIAU, Jean-Yves. $O$ suicídio segundo Arthur Schopenhauer. Disponível em: http://www.fflch.usp.br/df/site/publicacoes/ $\begin{array}{lllllllllllll}\mathrm{d} & \mathrm{i} & \mathrm{s} & \mathrm{c} & \mathrm{u} & \mathrm{r} & \mathrm{s} & \mathrm{o} & / & \mathrm{p} & \mathrm{d} & \mathrm{f} & /\end{array}$ D28_O_suicidio_segundo_Arthur_Schopen hauer.pdf Acesso em: 01 set. 2012. 11:32

HEGEL, G. W. F. Fenomenologia do Espírito. Petrópolis: Vozes, 2002. 549 p.

KANT, Immanuel. Fundamentos da Metafísica dos Costumes. Rio de Janeiro: Editora Tecnoprint 
Diego Carlos Damasceno

LEGIÃO URBANA. As quatro estações: Quando o Sol Bater na Janela do Teu Quarto. EMI Music, 1989, f. 4

NIETZSCHE, F. Genealogia da Moral. São Paulo: Companhia das Letras, 2009.

SCHOPENHAUER, Arthur. Dores do mundo. Salvador: Livraria Progresso Editora. Temas de Nosso Tempo; 1955 , Metafísica do amor, metafísica da morte, Trad. Jair Barbosa. São Paulo, Martins fontes, 2000 , O mundo como vontade $e$ representação. Rio de Janeiro: Contraponto, 2001. , O vazio da existência. Tradução: André Díspore Cancian. Disponíve 1 e m <htp:// ww w.imagomundi.com.br/filo/ schopenhauer_vazio.pdf $\geq$ Acesso em: 08 jun. 2012. 17:42 